\title{
Metabolic Syndrome Risk Factors and Physical Activity in Middle-Aged Women
}

\author{
Pao-Yu Wang ${ }^{1}$, Lee-Ing Tsao ${ }^{1}$, Mei-Hsiang Lin ${ }^{1} \&$ Chin-Ying Lee ${ }^{2}$ \\ ${ }^{1}$ Department of Nursing, National Taipei University of Nursing and Health Sciences, Taipei, Taiwan \\ ${ }^{2}$ Department of Superintendent/ Community medicine, Landseed International Hospital, Taoyuan, Taiwan \\ Correspondence: Prof. Lee-Ing Tsao, Department of Nursing, National Taipei University of Nursing and Health \\ Sciences, No.365, Ming-te Road, Poitou District, Taipei City, Taiwan. Tel: 886-2-2822-7101.
}

Received: November 13, 2019

Accepted: December 7, 2019

Online Published: December 12, 2019

doi:10.20849/ijsn.v4i4.669

URL: https://doi.org/10.20849/ijsn.v4i4.669

\begin{abstract}
Aim: The purpose of this study was to explore the correlation between physical activity and metabolic syndrome risk factors middle-aged women.

Methods: A cross-sectional survey of 101 middle-aged women with metabolic syndrome risk factors were recruited from a regional teaching hospital in Taiwan. Surveys were conducted using a demographic questionnaire, and the Taiwanese version of the self-administered short version of the International Physical Activity Questionnaire.

Results: The research results indicate that (1) $69 \%$ of the Women with metabolic syndrome were mostly in postmenopause, and the most common risk factor for metabolic syndrome was abdominal obesity (80.2\%). (2) Fasting blood glucose $(\mathrm{FBG}) \geq 100 \mathrm{mg} / \mathrm{dl}$ and the level of physical activity showed significantly differences $\left(\chi^{2}=\right.$ $6.1, \mathrm{p}<.05)$. (3)The total metabolic equivalents (METs) of physical activities of having or no having metabolic syndrome women showed significantly different, no having metabolic syndrome women higher then metabolic syndrome women $(t=2.23, p<.05)$. (4) The predictor of waist circumference $\geq 80 \mathrm{~cm}$ is basal metabolic index $(\mathrm{BMI})(\mathrm{OR}=3.46 ; 95 \% \mathrm{CI}=1.61,7.46)(\mathrm{p}<.05)$, the predictor of $\mathrm{FBG} \geq 100 \mathrm{mg} / \mathrm{dl}$ is insufficient physical activity $(\mathrm{OR}=11.29 ; 95 \% \mathrm{CI}=1.72,73.82)(\mathrm{p}<.05)$, and the predictors of metabolic syndrome are BMI $(\mathrm{OR}=$ $1.68 ; 95 \% \mathrm{CI}=1.33,2.08)$, menopause $(\mathrm{OR}=12.3 ; 95 \% \mathrm{CI}=1.25,120.68)$, and postmenopause $(\mathrm{OR}=42.97$; $95 \% \mathrm{CI}=2.22,831.41)(\mathrm{p}<.05)$.

Conclusions: This study recommends that to prevent metabolic syndrome, middle-aged women should adopt an active lifestyle, actively control their weight, and a minimum of $150 \mathrm{~min}$ of moderate-intensity physical activity per week or $75 \mathrm{~min}$ of high-intensity physical activity. This result is a potentially crucial reference for healthcare professionals in their care of patients with metabolic syndrome.
\end{abstract}

Keywords: metabolic syndrome, physical activities, middle-aged women

\section{Introduction}

According to Taiwan's Ministry of Health and Welfare (2019), among the ten major causes of death in women, four diseases (heart disease, cerebrovascular disease, diabetes, and hypertensive diseases) were related to metabolic syndrome. Wang, Wu, Su, Lin, and Lee (2019) noted that diseases caused by metabolic abnormality are a threat to public health and a great burden to families and society.

Metabolic syndrome is a term encompassing traits that increase the risk of diseases (Samson \& Garber, 2014). Research has shown that compared with those with no metabolic syndrome, people with metabolic syndrome are 2.35, 2.27, and 2.4 times more likely to develop cardiovascular disease (CVD), stroke, and CVD mortality, respectively (Mottillo et al., 2010). The risk factors include abdominal obesity, dyslipidemia (elevated triglycerides, low high-density lipoprotein [HDL]), high blood glucose, and hypertension (Kaaja, 2008). Grundy et al. (2005) noted that the US National Cholesterol Education Program Adult Treatment Panel III (NCEP ATP III) defines metabolic syndrome as conformance to three or more of the abnormalities in the NCEP ATP III's guidelines. The guidelines pertain to (1) abdominal obesity (a waist circumference (WC) $\geq 102 \mathrm{~cm}$ and $\geq 88 \mathrm{~cm}$ for men and women, respectively), (2) blood pressure (a systolic blood pressure (SBP) $\geq 130 \mathrm{mmHg}$, diastolic blood pressure (DBP) $\geq 85 \mathrm{mmHg}$, or the receiving hypertension medication and history of hypertension), (3) 
blood glucose (a fasting blood glucose (FBG) $\geq 100 \mathrm{mg} / \mathrm{dl}$ or the taking of diabetes medication), (4) triglycerides $(\geq 150 \mathrm{mg} / \mathrm{dl}$ or the taking of triglycerides medication), (5) HDL $(<40 \mathrm{mg} / \mathrm{dl}$ and $<50 \mathrm{mg} / \mathrm{dl}$ in men and women, respectively).

Middle-aged women tend to gain weight and have an increasing waistline due to decreased basal metabolism and physical activity; these increase their risk of metabolic syndrome (Lin, 2012). Yeh, Chang, and Pan (2011) conducted a survey on metabolic syndrome in Taiwan and observed a $15.1 \%$ prevalence rate for metabolic syndrome in women aged 31-44 years, which increased to $48.4 \%$ for those aged $45-64$ years. Cho et al. (2008) noted that first, women had the highest risk of developing hypertension at 5-9 years after menopause, second, women who have stopped menstruating for less than 5 years had an increased risk of abdominal obesity and high blood glucose, and third, women who have stopped menstruating for 10-14 years had an increased risk of high triglycerides. Thus, the prevalence rate for metabolic syndrome in women generally increases with age (Prasad, Kabir, Dash, \& Das, 2012).

The pathogenesis of metabolic syndrome is closely related to dietary factors and a sedentary lifestyle (Kaaja, 2008). However, women in developed societies, having to juggle between work and family, often mistake work as exercise or use a lack of time to excuse a sedentary lifestyle (Lin, 2012). Zając-Gawlak et al. (2017) noted that sedentary physical behavior and low physical activity increase the incidence of metabolic syndrome, and that relative to low physical activity, high physical activity lowers the risk of metabolic syndrome by 4 times. Wu, Fisher-Hoch, Reininger, and McCormick (2016) observed that the weekly performance of 150 min of moderateand high-intensity physical activity ( $\geq 600$ metabolic equivalent [MET] adjusted minutes) reduced the risk of developing metabolic syndrome by 36\%; performing more than 743 METs of moderate- and high-intensity physical activity per week reduced the risk of developing metabolic syndrome by $37 \%$. Related studies have confirmed that the inclusion of aerobic exercises during exercise potentially improves metabolic syndrome risk factors (Ostman et al., 2017). Therefore, an active lifestyle is vital for the prevention and treatment of metabolic syndrome (Yoo et al., 2014).

Therefore, this study examined the correlation between metabolic syndrome risk factors and physical activity in middle-aged women (in addition to the predictors of metabolic syndrome), as a reference to better assist middle-aged women with metabolic syndrome risk factors through increasing their physical activity.

\section{Method}

\subsection{Research Design}

This cross-sectional study employed a self-administered questionnaire survey. The study recruited patients that met the inclusion criteria at a free adult health checkup clinic and outpatient clinic of the metabolism and endocrinology division of a regional teaching hospital in Northern Taiwan. As for the inclusion criteria, research participants had to be (1) a woman aged 40-60 years; (2) having one of the metabolic syndrome risk factors; (3) conscious and can read or communicate in Mandarin and Taiwanese; (4) willing to participate in the study; (5) free of hormone therapy, mental illness, thyroid disease, and menopause caused by hysterectomy and oophorectomy; (6) willing to answer the study's questionnaire. Convenience sampling was used for data collection; 101 participates were recruited.

\subsection{Demographic Variables}

The demographic data included those on age, level of education, BMI, and menopausal stage.

\subsection{Metabolic Syndrome Risk Factors}

The guidelines for metabolic syndrome in this study are based on the following metabolic syndrome guidelines stipulated by Taiwan's Health Promotion Administration, Ministry of Health and Welfare (2007):

1. Abdominal obesity (for women: $\mathrm{WC} \geq 80 \mathrm{~cm}$ ).

2. High Blood pressure ( $\mathrm{SBP} \geq 130 \mathrm{mmHg}, \mathrm{DBP} \geq 85 \mathrm{mmHg}$, or the taking of hypertension medication).

3. High blood glucose ( $\mathrm{FBG} \geq 100 \mathrm{mg} / \mathrm{dl}$ or the taking of diabetes medication).

4. High triglycerides (triglycerides $\geq 150 \mathrm{mg} / \mathrm{dl}$ or the taking of hypolipidemic drugs).

5. Low HDL (for women: $<50 \mathrm{mg} / \mathrm{dl}$ ).

In this study, a person has metabolic syndrome risk factors if they satisfy any one of these criteria.

\subsection{International Physical Activity Questionnaires}

This study used the Taiwanese version of the self-administered short version International Physical Activity 
Questionnaires (IPAQ), authorized by the Health Promotion Administration, Ministry of Health and Welfare, Executive Yuan. Liu (2004) formulated this version of the IPAQ: they translated the original IPAQ to Chinese and classified its items according to the everyday activities of Taiwanese people. A reliability and validity test was conducted for the questionnaire, using 141 participants aged 18-65 years. The content validity score of the Chinese and English version of the IPAQ was greater than $98 \%$. The intrinsic correlation of the goodness of fit values for the language and similarity of meaning were $0.71-0.86$, indicating that this version of the IPAQ has excellent stability. In a Spearman's rho correlation test, the test-retest reliability was 0.67 . The IPAQ has seven questions, including two questions on the time spent daily on high-intensity physical activities in the last 7 days, two questions on moderate-intensity physical activities, two questions on walking, and one question on the time spent sitting daily. In this study, the method of calculation was to first take, for each participant, the values for the time spent on high-intensity physical activity, moderate-intensity physical activity, and walking (in the last 7 days). Subsequently, to calculate the total physical activity (METs in min/wk) for the last 7 days, the MET value for each type of physical activity (the MET values for high-intensity activity, moderate-intensity activity, and walking are 8.0,4.0, and 3.3, respectively) was multiplied by the time spent on the respective physical activity. Subsequently, each person's quantity of physical activity was obtained by summing across the three activity types; each person was then classified according to those who engaged in high physical activity, sufficient physical activity, and insufficient physical activity.

\subsection{Data Analysis}

The study used SPSS17.0 for statistical analysis. The descriptive statistics used in the study were the frequency, percentage, mean, and standard deviation. A Chi-square test and $t$ test were used to determine the extent of each metabolic syndrome in the middle-aged women and the difference between women with respect to metabolic syndrome and physical activity. Logistic regression was used to analyze the predictors of metabolic syndrome and metabolic syndrome risk factors. A p value $<.05$ was considered statistically significant.

\subsection{Ethical Considerations}

This study was approved by the institutional review board of a regional hospital in Taiwan (No. 099-E-14). The content of the consent form was explained verbally to the research subject prior to recruitment. The purpose and process of this study were explained in detail, and informed consent was obtained from the subject. The subject could withdraw at any time during the course of the study.

\section{Results}

\subsection{Demographics of Research Subjects and the Distribution of Metabolic Syndrome Risk Factors}

As displayed in Table 1, the average age of participants was $52.3 \pm 6.2$ years, most participants were in the postmenopausal stage ( 57 participants, $56.4 \%$ ), and the number of women with metabolic syndrome was 56 $(55.4 \%)$.

Table 1. Demographics of research subjects $n=101$

\begin{tabular}{lll}
\hline Variables & $\mathrm{n}(\%)$ & Mean \pm SD \\
\hline Age & & $52.3 \pm 6.2$ \\
\hline$\leq 44$ year & $17(16.8)$ & \\
\hline $45-50$ year & $21(20.8)$ & \\
\hline $51-55$ year & $17(16.8)$ & \\
\hline $56-60$ year & $46(45.5)$ & \\
\hline Educational degree & $21(20.8)$ & \\
\hline Junior high school & $27(26.7)$ & \\
\hline High school & $53(52.5)$ & \\
\hline University & & \\
\hline BMI & $29(28.7)$ & \\
\hline Normal $18.5 \leq$ BMI $<24$ & $33(32.7)$ & \\
\hline Overweight $24 \leq$ BMI $<27$ & $39(38.6)$ & \\
\hline Obesity BMI $\geq 27$ & & \\
\hline
\end{tabular}




\begin{tabular}{ll}
\hline Menopause stage & $25(24.8)$ \\
\hline Premenopausal & $19(18.8)$ \\
\hline Menopause & $57(56.4)$ \\
\hline Postmenopause & \\
\hline Number of Metabolic Syndrome risk factors & $10(9.9)$ \\
\hline One & $35(34.7)$ \\
\hline Two & $26(25.7)$ \\
\hline Three & $20(19.8)$ \\
\hline Four & $10(9.9)$ \\
\hline Five & \\
\hline Metabolic Syndrome & $56(55.4)$ \\
\hline$\geq$ three & $45(44.6)$ \\
\hline$<$ two
\end{tabular}

Abbreviation: SD, standard deviation

As displayed in Table 2, the numbers of women with abdominal obesity (WC $\geq 80 \mathrm{~cm}$ ), an FBG $\geq 100 \mathrm{mg} / \mathrm{dl}$, a $\mathrm{HDL}<50 \mathrm{mg} / \mathrm{dl}$, triglycerides $(\geq 150 \mathrm{mg} / \mathrm{dl})$, an SBP $\geq 130 \mathrm{mmHg}$, and a DBP $\geq 85 \mathrm{mmHg}$ were $81(80.2 \%), 75$ (74.3\%), 39 (38.6\%), $32(31.75 \%), 56(55.4 \%)$, and $24(23.8 \%)$, respectively.

Table 2. The distribution of metabolic syndrome risk factors $n=101$

\begin{tabular}{|c|c|c|c|c|}
\hline \multirow[t]{2}{*}{ Variables } & \multicolumn{3}{|l|}{$\mathrm{n}(\%)$} & \multirow[t]{2}{*}{ Mean $\pm S D$} \\
\hline & Normal & Anomaly & Not taking blood & \\
\hline \multicolumn{5}{|l|}{ Abdominal obesity } \\
\hline Waistline $<79 \mathrm{~cm}$ & $20(19.8)$ & & & $71.5 \pm 6.1$ \\
\hline Waistline $\geq 80 \mathrm{~cm}$ & & $81(80.2)$ & & $88.8 \pm 7.6$ \\
\hline \multicolumn{5}{|l|}{ Triglyceride } \\
\hline$<149 \mathrm{mg} / \mathrm{dl}$ & $64(63.4)$ & & & $88.9 \pm 32.8$ \\
\hline \multirow[t]{2}{*}{$\geq 150 \mathrm{mg} / \mathrm{dl}$} & & $32(31.7)$ & & $231.4 \pm 102.1$ \\
\hline & & & $5(5)$ & \\
\hline \multicolumn{5}{|l|}{ Fasting blood sugar } \\
\hline$<99 \mathrm{mg} / \mathrm{dl}$ & $20(19.8)$ & & & $87.2 \pm 7.9$ \\
\hline \multirow[t]{2}{*}{$\geq 100 \mathrm{mg} / \mathrm{dl}$} & & $75(74.3)$ & & $156.1 \pm 49.2$ \\
\hline & & & $6(5.9)$ & \\
\hline \multicolumn{5}{|l|}{ HDL-C } \\
\hline$<50 \mathrm{mg} / \mathrm{dl}$ & & $39(38.6)$ & & $41.6 \pm 4.7$ \\
\hline \multirow[t]{2}{*}{$>50 \mathrm{mg} / \mathrm{dl}$} & $33(32.7)$ & & & $62.2 \pm 14.4$ \\
\hline & & & $29(28.7)$ & \\
\hline \multicolumn{5}{|c|}{ Systolic blood pressure } \\
\hline$<129 \mathrm{mmHg}$ & $45(44.6)$ & & & $120.4 \pm 6.9$ \\
\hline$\geq 130 \mathrm{mmHg}$ & & $56(55.4)$ & & $139.8 \pm 6.9$ \\
\hline \multicolumn{5}{|c|}{ Diastolic blood pressure } \\
\hline$<84 \mathrm{mmHg}$ & $77(76.2)$ & & & $74.1 \pm 6.2$ \\
\hline$\geq 85 \mathrm{mmHg}$ & & $24(23.8)$ & & $89.4 \pm 3.7$ \\
\hline
\end{tabular}

Abbreviation: SD, standard deviation 
3.2 Presence or Absence of Metabolic Syndrome Risk Factors, and the Association Between Metabolic Syndrome and Physical Activity

As detailed in Table 3, FBG was significantly associated with physical activity $(\chi 2=6.1, \mathrm{p}=.04)$, with an FBG $\geq 100 \mathrm{mg} / \mathrm{dl}$ mostly due to insufficient physical activity. The variables pertaining to WC, triglycerides, HDL, SBP, and DBP were not significantly associated with physical activity.

Table 3. Presence or absence of metabolic syndrome risk factors, and the association between metabolic syndrome and physical activity

\begin{tabular}{|c|c|c|c|c|c|c|c|c|c|c|c|c|c|c|c|}
\hline \multirow[t]{2}{*}{ Variables } & & \multicolumn{2}{|c|}{ waistline $\geqq 80 \mathrm{~cm}$} & \multicolumn{2}{|c|}{$\begin{array}{l}\text { Triglyceride } \\
\geqq 150 \mathrm{mg} / \mathrm{dL}\end{array}$} & \multicolumn{2}{|c|}{$\begin{array}{l}\text { Fasting } \quad \begin{array}{r}\text { blood } \\
\text { sugar } \geqq 100 \mathrm{mg} / \mathrm{dl}\end{array}\end{array}$} & \multicolumn{2}{|c|}{ HDL-C $<50 \mathrm{mg} / \mathrm{dl}$} & \multicolumn{2}{|c|}{$\begin{array}{l}\text { Systolic } \\
\text { pressure } \\
130 \mathrm{mmHg}\end{array}$} & $\begin{array}{l}\text { Diastolic } \\
\text { pressure } \\
85 \mathrm{mmHg}\end{array}$ & $\begin{array}{r}\text { blood } \\
\geqq\end{array}$ & \multicolumn{2}{|c|}{$\begin{array}{l}\text { Metabolic } \\
\text { Syndrome }\end{array}$} \\
\hline & & $\begin{array}{l}\text { Yes } \\
\mathrm{n}=81\end{array}$ & $\begin{array}{l}\text { No } \\
n=20\end{array}$ & $\begin{array}{l}\text { Yes } \\
\mathrm{n}=32\end{array}$ & $\begin{array}{l}\text { No } \\
\mathrm{n}=64\end{array}$ & $\begin{array}{l}\text { Yes } \\
\mathrm{n}=75\end{array}$ & $\begin{array}{l}\text { No } \\
\mathrm{n}=20\end{array}$ & $\begin{array}{l}\text { Yes } \\
\mathrm{n}=39\end{array}$ & $\begin{array}{l}\text { No } \\
\mathrm{n}=33\end{array}$ & $\begin{array}{l}\text { Yes } \\
\mathrm{n}=56\end{array}$ & $\begin{array}{l}\text { No } \\
\mathrm{n}=45\end{array}$ & $\begin{array}{l}\text { Yes } \\
n=24\end{array}$ & $\begin{array}{l}\text { No } \\
\mathrm{n}=77\end{array}$ & $\begin{array}{l}\text { Yes } \\
\mathrm{n}=56\end{array}$ & $\begin{array}{l}\text { No } \\
\mathrm{n}=45\end{array}$ \\
\hline \multirow[t]{3}{*}{$\begin{array}{l}\text { Physical } \\
\text { Activity }\end{array}$} & $\begin{array}{l}\text { High/ } \\
\text { sufficient }\end{array}$ & $\begin{array}{l}45 \\
(56 \%)\end{array}$ & $\begin{array}{l}13 \\
(65 \%)\end{array}$ & $\begin{array}{l}20 \\
(62 \%)\end{array}$ & $\begin{array}{l}36 \\
(56 \%)\end{array}$ & $\begin{array}{l}36 \\
(48 \%)\end{array}$ & $\begin{array}{l}15 \\
(80 \%)\end{array}$ & $\begin{array}{l}18 \\
(47 \%)\end{array}$ & $\begin{array}{l}21 \\
(64 \%)\end{array}$ & $\begin{array}{l}29 \\
(52 \%)\end{array}$ & $\begin{array}{l}29 \\
(64 \%)\end{array}$ & $\begin{array}{l}16 \\
(66 \%)\end{array}$ & $\begin{array}{l}43 \\
(56 \%)\end{array}$ & $\begin{array}{l}27 \\
(48 \%)\end{array}$ & $\begin{array}{l}34 \\
(69 \%)\end{array}$ \\
\hline & insufficient & $\begin{array}{l}36 \\
(44 \%)\end{array}$ & $\begin{array}{l}7 \\
(35 \%)\end{array}$ & $\begin{array}{l}12 \\
(38 \%)\end{array}$ & $\begin{array}{l}28 \\
(44 \%)\end{array}$ & $\begin{array}{l}39 \\
(52 \%)\end{array}$ & $\begin{array}{l}5 \\
(20 \%)\end{array}$ & $\begin{array}{l}21 \\
(53 \%)\end{array}$ & $\begin{array}{l}12 \\
(36 \%)\end{array}$ & $\begin{array}{l}27 \\
(48 \%)\end{array}$ & $\begin{array}{l}16 \\
(36 \%)\end{array}$ & $\begin{array}{l}9 \\
(34 \%)\end{array}$ & $\begin{array}{l}34 \\
(44 \%)\end{array}$ & $\begin{array}{l}29 \\
(52 \%)\end{array}$ & $\begin{array}{l}14 \\
(31 \%)\end{array}$ \\
\hline & $\chi^{2}(P)$ & $.58(.61)$ & & $.99(.60)$ & & $6.1(.04)$ & & $3.32(.1$ & & $1.63(.22)$ & & $.33(.64)$ & & $4.36(.06$ & \\
\hline
\end{tabular}

Note: $\mathrm{n}=101$

\subsection{The Presence and Absence of Metabolic Syndrome Differed According to the Total METs of Physical Activity}

As presented in Table 4, the presence and absence of metabolic syndrome significantly differed according to the total METs of physical activity $(\mathrm{t}=2.23, \mathrm{p}<.05)$. Among participants, those who had no metabolic syndrome had higher total METs relative to those with metabolic syndrome (1216.14 \pm 1471.72 vs. $674.94 \pm 764.71)$.

Table 4. The presence and absence of metabolic syndrome differed according to the total METs of physical activity $(\mathrm{N}=101)$

\begin{tabular}{llll}
\hline Variables & \multicolumn{2}{l}{ Metabolic Syndrome } & $t(P)$ \\
\cline { 2 - 3 } & $\mathrm{Yes}(\mathrm{n}=56)$ & $\mathrm{No}(\mathrm{n}=45)$ & \\
\hline Total Physical Activity METs & $674.94 \pm 764.71$ & $1216.14 \pm 1471.72$ & $2.23(.02)$ \\
\hline
\end{tabular}

Abbreviation: SD, standard deviation; M, mean

\subsection{Predictors of Metabolic Syndrome Risk Factors}

The study used the statistically significant predictors ("basic attributes" and "physical activity") as independent variables and the metabolic syndrome risk factors ("presence or absence of WC $\geq 80 \mathrm{~cm}$," "presence or absence of FBG $\geq 100 \mathrm{mg} / \mathrm{dl}$," and "presence or absence of SBP $\geq 85 \mathrm{mmHg}$ ") as dependent variables in a logistic regression. In the regression results, a $\mathrm{WC} \geq 80 \mathrm{~cm}$ and the predictor variable of BMI was statistically significant $(\mathrm{p}<.05)$, with BMI having an OR value of 3.46--meaning that for every unit $(\mathrm{kg} / \mathrm{m} 2)$ increase in BMI, the risk ratio of those with WC $\geq 80 \mathrm{~cm}$ increased by 3.46 times. A fasting blood glucose $\geq 100 \mathrm{mg} / \mathrm{dl}$ and the predictor variable of insufficient physical activity were statistically significant $(\mathrm{p}<.05)$, with insufficient physical activity having an OR value of 11.29--meaning that comparing those who had sufficient physical activity, those with insufficient physical activity having an $\mathrm{FBG} \geq 100 \mathrm{mg} / \mathrm{dl}$ risk ratio was 11.29 times higher (Table 5). 
Table 5. Predictors of metabolic syndrome risk factors

\begin{tabular}{|c|c|c|c|}
\hline Variables(Baseline category) & $\mathrm{B}$ & $\mathrm{OR}(95 \% \mathrm{CI})$ & $P$ \\
\hline \multicolumn{4}{|l|}{${ }^{\mathrm{a}}$ Waistline $\geq 80 \mathrm{~cm}(\mathrm{No})$} \\
\hline Age & .10 & $1.11(.67,1.83)$ & .68 \\
\hline BMI & 1.24 & $3.46(1.61,7.46)$ & .00 \\
\hline \multicolumn{4}{|l|}{ Menopause stage(Premenopausal) } \\
\hline Menopause & -20.7 & .00 & .99 \\
\hline Postmenopause & -18.6 & .00 & .99 \\
\hline \multicolumn{4}{|l|}{${ }^{\mathrm{b}}$ Fasting blood sugar $\geq 100 \mathrm{mg} / \mathrm{dl}(\mathrm{No})$} \\
\hline Age & .09 & $1.10(.79,1.52)$ & .55 \\
\hline \multicolumn{4}{|l|}{ Menopause stage(Premenopausal) } \\
\hline Menopause & 2.03 & $7.67(.38,152.72)$ & .18 \\
\hline Postmenopause & 2.50 & $12.24(.14,003.69)$ & .26 \\
\hline \multicolumn{4}{|l|}{ Physical Activity(Enough) } \\
\hline High & 1.52 & $4.60(.02,950.23)$ & .57 \\
\hline Inadequate & 2.42 & $11.29(1.72,73.82)$ & .01 \\
\hline \multicolumn{4}{|l|}{${ }^{\mathbf{c}}$ Diastolic blood pressure $\geq 85 \mathrm{mmHg}(\mathrm{No})$} \\
\hline Age & -.08 & $.91(.77,1.09)$ & .33 \\
\hline BMI & .14 & $1.15(.98,1.35)$ & .07 \\
\hline \multicolumn{4}{|l|}{ Menopause stage(Premenopausal) } \\
\hline Menopause & .22 & $1.25(.17,9.09)$ & .82 \\
\hline Postmenopause & .31 & $1.37(.10,18.09)$ & .80 \\
\hline \multicolumn{4}{|l|}{${ }^{\mathrm{a}}$ Omnibus Tests: Chi-square $=74.63, \mathrm{P} .00$} \\
\hline \multicolumn{4}{|l|}{${ }^{\mathrm{b}}$ Omnibus Tests: Chi-square $=47.69, \mathrm{P} .00$} \\
\hline${ }^{c}$ Omnibus Tests: Chi-square=22.83 , P.00 & & & \\
\hline
\end{tabular}

a. 96 cases effective samples; b. 85 cases effective samples; c. 83 cases effective samples

\subsection{Predictors of Metabolic Syndrome}

According to Table 6, metabolic syndrome and the predictor variables of "BMI" "menopause," and "postmenopause" were statistically significant $(\mathrm{p}<.05)$, which means that for every unit $(\mathrm{kg} / \mathrm{m} 2)$ increase in BMI, the metabolic syndrome risk ratio increased by 1.68 times. Compared with women in premenopause, the metabolic syndrome risk ratio for women in menopause was 12.3 times higher. Compared with women in premenopause, the metabolic syndrome risk ratio of those in postmenopause was 42.97 times higher.

Table 6. Predictors of metabolic syndrome

\begin{tabular}{llll}
\hline Variables(Baseline category) & B & OR $(95 \% \mathrm{CI})$ & $\boldsymbol{P}$ \\
\hline Age & -.00 & $.99(.82,1.21)$ & .97 \\
\hline BMI & .51 & $1.68(1.33,2.08)$ & .00 \\
\hline Menopause stage(Premenopausal) & & & .03 \\
\hline Menopause & 2.51 & $12.3(1.25,120.68)$ & .01 \\
\hline Postmenopause & 3.76 & $42.97(2.22,831.41)$ & .11 \\
\hline Total Physical Activity METs & .00 & $1.00(.99,1.00)$ & \\
\hline Omnibus Tests: Chi-square=54.37, $\mathrm{p}=.00$ & & & \\
\hline
\end{tabular}

81 cases effective samples 


\section{Discussion}

The aim of this study was to discuss the correlation between metabolic syndrome risk factors and physical activity in middle-aged women. The study found that metabolic syndrome was most prevalent in postmenopausal women (69\%); this result is similar to those of Heidari et al. (2010) and Pandey et al. (2010). Heidari et al. (2010) studied metabolic syndrome in postmenopausal women and found that postmenopausal women were more prone to developing metabolic syndrome than women in premenopause and the early stage of menopause. This implies that to reduce their risk of metabolic syndrome, postmenopausal women should make lifestyle changes to control their body weight, blood glucose, blood pressure, and blood lipid levels. Pandey et al. (2010) studied metabolic syndrome in menopausal women and found that more women developed metabolic syndrome during postmenopause. Therefore, it is recommended that postmenopausal women should actively adopt a healthier lifestyle to lower their risk of developing metabolic syndrome.

Regarding metabolic syndrome risk factors, studies have found that most factors were associated with abdominal obesity, a result consistent with those of Arai et al. (2010). Arai et al. (2010) studied the prevalence of metabolic syndrome in elderly and middle-aged people and discovered that abdominal obesity was the most crucial metabolic syndrome risk factor in women aged 40-64 years. Davies, Heaney, Recker, Barger, and Lappe (2001) observed that women in pre and postmenopause gained weight at a rate of $0.43 \%$ annually. Lovejoy, Champagne, Jonge, Xie, and Smith (2008) noted that the accumulation of abdominal fat in women in pre and postmenopause increased with time. Thus, these findings strongly suggest that abdominal obesity in women is a significant cause of metabolic syndrome.

This study determined that FBG significantly differed in relation to physical activity; an FBG $\geq 100 \mathrm{mg} / \mathrm{dl}$ was mostly due to insufficient physical activity $(\mathrm{p}<.05)$. This result is similar to that of Turi, Codogno, Fernandes, and Monteiro (2016). Turi et al. (2016) studied the association between low physical activity and metabolic syndrome, in people aged 50 years, and determined that the time spent on physical activities was negatively and significantly correlated with diabetes, hypercholesterolemia, and high prevalence of metabolic syndrome. Additionally, Lee et al. (2012) evaluated the effects of a lack of exercise on major chronic diseases globally; the study noted that instances of a lack exercise comprised $7 \%$ of diabetes cases, $6 \%$ of heart disease cases, in addition to a greater number of cases of increased mortality and decreased life expectancy. Numerous studies have confirmed that physical activity can prevent and reverse the risk factors of metabolic syndrome. Myers, Kokkinos, and Nyelin (2019) noted that a minimum of 150 min of moderate-intensity physical activity per week or $75 \mathrm{~min}$ of high-intensity physical activity per week can significantly reduce the risks of metabolic syndrome.

The results of the present study also indicated that metabolic syndrome significantly $(p<.05)$ differed with respect to the total METs of physical activity: the total METs of those with no metabolic syndrome was higher than those with metabolic syndrome. This result is similar to those of Bilbeisi, Hosseini, and Djafarian (2017). Bilbeisi, Hosseini, and Djafarian (2017) found that women with metabolic syndrome averaged $710.6 \pm 1$ MET/wk of physical activity — which comprised mostly low physical activity (97\%) — and women with no metabolic syndrome averaged 2293.2 $\pm 1 \mathrm{MET} /$ wk of physical activity-which comprised mostly high physical activity (73.7\%). Thus, these findings strongly suggest that low physical activity and increased metabolic syndrome are correlated.

According to the results of this study, insufficient physical activity was a predictor of $\mathrm{FBG} \geq 100 \mathrm{mg} / \mathrm{dl}(\mathrm{OR}=$ 11.29; 95\% CI $=1.72,73.82)(\mathrm{p}<.05)$. Orchard et al. (2005) conducted a randomized trial on the relationship between lifestyle intervention and metabolic syndrome. They found that 3 years after the intervention, the group with the lifestyle intervention (which comprised at least $150 \mathrm{~min}$ of physical activity weekly and a low calorie, low fat diet) significantly improved metabolic risk factors, such as FBG, relative to the group with no lifestyle intervention.

According to the results of this study, BMI was the predictor of $\mathrm{WC} \geq 80 \mathrm{~cm}(\mathrm{OR}=3.46 ; 95 \% \mathrm{CI}=1.61,7.46)$ and metabolic syndrome $(\mathrm{OR}=1.68 ; 95 \% \mathrm{CI}=1.33,2.08)(\mathrm{p}<.05)$, similar to the results of Yen et al. (2007). Yen et al. (2007) found that the BMI of those with a WC $\geq 80 \mathrm{~cm}$ were mostly in the obese range, and further analysis indicated that for every 1 unit increase in BMI, the metabolic syndrome risk ratio increased by 1.41 times. Additionally, this study also determined that the predictors of metabolic syndrome include menopause $(\mathrm{OR}=12.3 ; 95 \% \mathrm{CI}=1.25,120.68)$ and postmenopause $(\mathrm{OR}=42.97 ; 95 \% \mathrm{CI}=2.22,831.41)(\mathrm{p}<.05)$. Heidari et al. (2010) studied metabolic syndrome in 1596 menopausal women in Iran, they found that the metabolic syndrome significantly differed in relation to menopausal stage. Among the participants their study, there were 303 women in premenopausal, 233 women in early menopausal and 987 women in postmenopausal. 136(44.9\%) were premenopausal women with metabolic syndrome, 135(57.9\%) were menopausal women with metabolic 
syndrome, and 634(64.3\%) were postmenopausal women with metabolic syndrome. These findings strongly suggest that, in comparison with premenopause, the risk of developing metabolic syndrome is higher during menopause and postmenopause. Drown (2006) determined that estrogen deficiency contributes to visceral fat distribution.

\section{Conclusion and Recommendation}

The purpose of this study was to investigate the correlation between metabolic syndrome risk factors and physical activity in middle-aged women (in addition to the predictors of metabolic syndrome). The results of the study indicate that an FBG $\geq 100 \mathrm{mg} / \mathrm{dl}$ was mostly due to insufficient physical activity, the total METs of those with no metabolic syndrome was higher than those with metabolic syndrome. We recommend that middle-aged women should actively adopt a healthy lifestyle during menopause and postmenopause to actively control their weight. Specifically, a minimum of $150 \mathrm{~min}$ of moderate-intensity physical activity per week or 75 min of high-intensity physical activity to prevent metabolic syndrome. This finding serves as a potential reference for healthcare professionals in their care of patients with metabolic syndrome.

\section{References}

Arai, H., Yamamoto, A., Matsuzawa, Y., Saito, Y., Yamada, N., Oikawa, S., ... Kita, T. (2010). Prevalence of the metabolic syndrome in elderly and middle-aged Japanese. Journal of Clinical Gerontology \& Geriatrics, 2(1), 42-47. https://doi.org/10.1016/j.jcgg.2010.10.011

Bilbeisi, A. H. El., Hosseini, S., \& Djafarian, K. (2017). The Association between Physical Activity and the Metabolic Syndrome among Type 2 Diabetes Patients in Gaza Strip, Palestine. Ethiopian Journal of Health Sciences, 27(3), 273-282. https://doi.org/10.4314/ejhs.v27i3.9

Cho, G. J., Lee, J. H., Park, H. T., Shin, J. H., Hong, S. C., Kim, T., ... Kim, S. H. (2008). Postmenopausal status according to years since menopause as an independent risk factor for the metabolic syndrome. Menopause, 15(3), 524-9. https://doi.org/10.1097/gme.0b013e3181559860

Davies, K. M., Heaney, R. P., Recker, R. R., Barger, L. M. J., \& Lappe, J. M. (2001). Hormones, weight change and menopause. International Journal of Obesity, 25(6), 874-879. https://doi.org/10.1038/sj.ijo.0801593

Drown, D. J. (2006). Women, menopause, and the metabolic syndrome. Progress in Cardiovascular Nursing, 21(1), 51-52. https://doi.org/10.1111/j.0197-3118.2006.04966.x

Grundy, S. M., Cleeman, J. I., Daniels, S. R., Donato, K. A., Eckel, R. H., Franklin, B. A., ... Costa, F. (2005). Diagnosis and management of the metabolic syndrome: an American Heart Association/National Heart, Lung, and Blood Institute Scientific Statement. Circulation, 112, 2735-2752. https://doi.org/10.1161/CIRCULATIONAHA.105.169404

Health Promotion Administration, Ministry of Health and Welfare. (2007). Judging criteria for adult metabolic syndrome. Retrieved from https:// https://www.hpa.gov.tw/Pages/Detail.aspx?nodeid=639\&pid=1219

Heidari, R., Sadeghi, M., Talaei, M., Rabiei, K., Mohammadifard, N., \& Sarrafzadegan, N. (2010). Metabolic syndrome in menopausal transition: Isfahan healthy heart program, a population based study. Diabetology Metabolic Syndrome, 2(59), 1-6. https://doi.org/10.1186/1758-5996-2-59

Kaaja, R. J. (2008). Metabolic syndrome and the menopause. Menopause International, 14(1), 21-25. https://doi.org/10.1258/mi.2007.007032

Lee, I. M., Shiroma, E. J., Lobelo, F., Puska, P., Blair, S. N., Katzmarzyk, P. T., \& Lancet Physical Activity Series Working Group. (2012). Effect of physical inactivity on major non-communicable diseases worldwide: an analysis of burden of disease and life expectancy. Lancet, 380(9838), 219-229. https://doi.org/10.1016/S0140-6736(12)61031-9

Lin, C. R. (2012). Effect of a Regular Community-based Physical Activity Program on Metabolic Parameters in Middle-aged Women. Tzu Chi Nursing Journal, 11(4), 84-94.

Liou, Y. M. (2004). Development and Verification of Validity and Reliability of the International Physical Activity Questionnaire Taiwan Version. Doctoral dissertation. Retrieved from https://scholars.lib.ntu.edu.tw/handle/123456789/156309

Lovejoy, J. C., Champagne, C. M., Jonge, L., Xie, H., \& Smith, S. R. (2008). Increased visceral fat and decreased energy expenditure during the menopausal transition. International Journal of Obesity, 32(6), 949-958. https://doi.org/10.1038/ijo.2008.25

Ministry of Health and Welfare. (2019). Statistical results of 107 year deaths in women. Retrieved from 
https://www.mohw.gov.tw/cp-4256-48057-1.html

Mottillo, S., Filion, K. B., Genest, J., Joseph, L., Pilote, L., Poirier, P., ... Eisenberg, M. J. (2010). The Metabolic Syndrome and Cardiovascular RiskA Systematic Review and Meta-Analysis. Journal of the American College of Cardiology, 56(14), 1113-1132. https://doi.org/10.1016/j.jacc.2010.05.034

Myers, J., Kokkinos, P., \& Nyelin, E. (2019). Physical Activity, Cardiorespiratory Fitness, and the Metabolic Syndrome. Nutrients, 11(7), 1652. https://doi.org/10.3390/nu11071652

Orchard, T. J., Temprosa, M., Goldberg, R., Haffner, S., Ratner, R., Marcovina, S., \& Fowler, S. (2005). The effect of metformin and intensive lifestyle intervention on the metabolic syndrome: The Diabetes Prevention Program randomized trial. Annals Internal of Medicine, 142, 611-619. https://doi.org/10.7326/0003-4819-142-8-200504190-00009

Ostman, C., Smart, N. A., Morcos, D., Duller, A., Ridley, W., \& Jewiss, D. (2017). The effect of exercise training on clinical outcomes in patients with the metabolic syndrome: a systematic review and meta-analysis. Cardiovascular Diabetology, 16(1). https://doi.org/1186/s12933-017-0590-y

Pandey, S., Srinivas, M., Agashe, S., Joshi, J., Galvankar, P., Prakasam, C. P., \& Vaidya, R. (2010). Menopause and metabolic syndrome: A study of 498 urban women from western India. Journal of Mid-Life Health, 1(2), 63-69. https://doi.org/10.4103/0976-7800.76214

Prasad, D. S., Kabir, Z., Dash, A. K., \& Das, B. C. J. (2012). Prevalence and risk factors for metabolic syndrome in Asian Indians: A community study from urban Eastern India. Journal of Cardiovascular Disease Research, 3(3), 204-211. https://doi.org/10.4103/0975-3583.98895

Samson, S. L., \& Garber, A. J. (2014). Metabolic Syndrome. Endocrinology \& Metabolism Clinics of North America, 43(1), 1-23. https://doi.org/10.1016/j.ecl.2013.09.009

Turi, B. C., Codogno, J. S., Fernandes, R. A., \& Monteiro, H. L. (2016). Low levels of physical activity and metabolic syndrome: cross-sectional study in the Brazilian public health system. Ciência \& Saúde Coletiva, 21(4), 1043-50. https://doi.org/10.1590/1413-81232015214.23042015

Wang, W. H., Wu, S. F. V., Su, C. C., Lin, C. C., \& Lee, M. C. (2019). Correlations Among Knowledge, Depression, and Quality of life in Patients with Metabolic Syndrome. Cheng Ching Medical Journal, 15(3), 24-33.

Wu, S., Fisher-Hoch, S. P., Reininger, B., Joseph, B., \& Cormick, M. C. (2016). Recommended Levels of Physical Activity Are Associated with Reduced Risk of the Metabolic Syndrome in Mexican-Americans. PloS One. https://doi.org/10.1371/journal.pone.0152896

Yeh, C. J., Chang, H. I., \& Pan, W. H. (2011). Time trend of obesity, the metabolic syndrome and related dietary pattern in Taiwan: from NAHSIT 1993-1996 to NAHSIT 2005-2008. Asia Pacific Journal of Clinical Nutrition, 20(2), 292-300.

Yen, Y. C., Huang, H. P., Hsueh, S. C., Lee, C. H., Hsu, H. Y., Chung, T. C., ... Yang, T. (2007). The Investigation of Relationship between Obesity Indices and Metabolic Syndrome among middle-aged and Elderly Adults in Pingtung Area. Chinese Journal of Occupational Medicine, 14(3), 149-160.

Yoo, K. B., Suh, H. J., Lee, M., Kim, J. H., Kwon, H. A., \& Park, E. C. (2014). Breakfast eating patterns and the metabolic syndrome: the Korea National Health and Nutrition Examination Survey (KNHANES) 2007-2009. Asia Pacific Journal of Clinical Nutrition, 23(1), 128-137.

Zając-Gawlak, I., Kłapcińska, B., Kroemeke, A., Pośpiech, D., Pelclová, J., \& Přidalová, M. (2017). Associations of visceral fat area and physical activity levels th the risk of metabolic syndrome in postmenopausal women. Biogerontology, 18(3), 357-366. https://doi.org/10.1007/s10522-017-9693-9

\section{Copyrights}

Copyright for this article is retained by the author(s), with first publication rights granted to the journal.

This is an open-access article distributed under the terms and conditions of the Creative Commons Attribution license (http://creativecommons.org/licenses/by/4.0/). 